\title{
Targeting of epidermal Langerhans cells with antigenic proteins: attempts to harness their properties for immunotherapy
}

\author{
Vincent Flacher · Florian Sparber • \\ Christoph H. Tripp • Nikolaus Romani • \\ Patrizia Stoitzner
}

Received: 20 June 2008 / Accepted: 12 July 2008 / Published online: 2 August 2008

(C) The Author(s) 2008

\begin{abstract}
Langerhans cells, a subset of skin dendritic cells in the epidermis, survey peripheral tissue for invading pathogens. In recent functional studies it was proven that Langerhans cells can present exogenous antigen not merely on major histocompatibility complexes (MHC)-class II molecules to $\mathrm{CD}^{+} \mathrm{T}$ cells, but also on MHC-class I molecules to $\mathrm{CD} 8^{+} \mathrm{T}$ cells. Immune responses against topically applied antigen could be measured in skin-draining lymph nodes. Skin barrier disruption or co-application of adjuvants was required for maximal induction of $\mathrm{T}$ cell responses. Cytotoxic $\mathrm{T}$ cells induced by topically applied antigen inhibited tumor growth in vivo, thus underlining the potential of Langerhans cells for immunotherapy. Here we review recent work and report novel observations relating to the potential use of Langerhans cells for immunotherapy. We investigated the potential of epicutaneous immunization strategies in which resident skin dendritic cells are loaded with tumor antigen in situ. This contrasts with current clinical approaches, where dendritic cells generated from progenitors in blood are loaded with tumor antigen ex vivo before injection into cancer patients. In the current study, we applied either fluorescently labeled
\end{abstract}

This article is a symposium paper from the conference

"Immunotherapy-From Basic Research to Clinical Applications," Symposium of the Collaborative Research Center (SFB) 685, held in Tübingen, Germany, 6-7 March 2008.

V. Flacher · F. Sparber $\cdot$ C. H. Tripp · N. Romani · P. Stoitzner $(\bowtie)$ Department of Dermatology and Venereology,

Innsbruck Medical University, Anichstrasse 35,

6020 Innsbruck, Austria

e-mail: Patrizia.stoitzner@i-med.ac.at

N. Romani

Kompetenzzentrum Medizin Tirol (CEMIT), Innsbruck, Austria

e-mail: nikolaus.romani@i-med.ac.at protein antigen or targeting antibodies against DEC-205/ CD205 and langerin/CD207 topically onto barrier-disrupted skin and examined antigen capture and transport by Langerhans cells. Protein antigen could be detected in Langerhans cells in situ, and they were the main skin dendritic cell subset transporting antigen during emigration from skin explants. Potent in vivo proliferative responses of $\mathrm{CD}^{+}{ }^{+}$and $\mathrm{CD} 8^{+} \mathrm{T}$ cells were measured after epicutaneous immunization with low amounts of protein antigen. Targeting antibodies were mainly transported by langerin ${ }^{+}$migratory dendritic cells of which the majority represented migratory Langerhans cells and a smaller subset the new langerin $^{+}$dermal dendritic cell population located in the upper dermis. The preferential capture of topically applied antigen by Langerhans cells and their ability to induce potent $\mathrm{CD}^{+}$and $\mathrm{CD}^{+} \mathrm{T}$ cell responses emphasizes their potential for epicutaneous immunization strategies.

Keywords Dendritic cells · Migration · Vaccination · Epicutaneous $\cdot$ Langerhans cells $\cdot$ Transcutaneous
Abbreviations
CFSE Carboxy-fluorescein diacetate succinimidyl ester
MHC Major histocompatibility complexes
OVA Ovalbumin
TLR Toll like receptors

\section{Langerhans cells: an introduction}

Exactly 140 years ago Paul Langerhans discovered the network of Langerhans cells in the epidermis of the skin and assumed that they were nerve cells given that they exhibited very long extensions and thin long cell bodies, and that they were detected by a histochemical staining method used 
for the identification of nerve cells at that time. Many years later Ralph Steinman and Zanvil Cohn described a new cell type in murine spleen that displayed long pseudopods which made them look stellate or dendritic, hence the name "dendritic cells" [48, 50]. This new cell type was found in other tissues such as bone marrow, lymph nodes and many more. Shortly thereafter, the "nerve cells" described by Paul Langerhans cells were re-investigated and found to be of bone marrow origin and share markers with other cells of the immune system. In vitro studies demonstrated that Langerhans cells stimulated allogeneic $\mathrm{T}$ cells, thus classifying them as a member of the dendritic cells system that resides in the epidermis (reviewed in [42, 43]).

\section{Functions of Langerhans cells}

Studies performed in Ralph Steinman's lab revealed that Langerhans cells isolated from the epidermis matured into powerful immunostimulatory cells during in vitro culture [44]. Besides, Langerhans cells proved to be capable of processing protein antigen and presenting immunogenic peptides on the cell surface by major histocompatibility complexes (MHC)-class II molecules to naïve $\mathrm{CD}^{+}{ }^{+} \mathrm{T}$ cells [41]. Processing capacity was down-regulated upon in vitro culture. These seminal findings gave birth to the idea to consider Langerhans cells as a model to investigate the role of dendritic cells in general.

We demonstrated recently that Langerhans cells capture exogenous skin-derived antigen, process it and cross-present antigenic peptides on MHC-class I to $\mathrm{CD}^{+} \mathrm{T}$ cells in vitro and in vivo [53]. Langerhans cells thus represent a major subset of skin dendritic cells that, together with dermal dendritic cells, are equipped to fulfill the task of surveying skin for invading pathogens and stimulating immune responses against skin-borne pathogens [43]. On the other hand, there is some evidence that cutaneous dendritic cells may play an important role in maintaining peripheral tolerance against self-antigens expressed in the skin [60]. Thus, the ability of Langerhans cells to induce immunity and tolerance would ensure that both responses are balanced [51]. It should be emphasized, however, that most of our knowledge on the functions of Langerhans cells was derived from in vitro studies.

\section{Current views on Langerhans cell function in vivo}

The Langerhans cell community was quite surprised by recent findings about the absence of in vivo antigen presentation by Langerhans cells in case of some viral and parasitic infections of the skin and mucosa [2, 40, 64]. The almost concomitant development of murine Langerhans cell ablation models [4, 23, 24] made it possible to investigate the immunogenicity of Langerhans cells in skin immune responses in vivo. Surprisingly, the first studies performed with these models caused more uncertainty than certainty. Contact hypersensitivity responses had different outcomes in the three models. Some of the confusion could be resolved recently, and Langerhans cells were indeed shown to be mandatory for the induction of contact hypersensitivity [5]. Moreover, a novel subset of dermal dendritic cells that expresses the Langerhans cell marker langerin/CD207, a C-type lectin receptor [57], was identified and described to participate in skin immune responses $[8,17,37]$. There is some indication that Langerhans cells and dermal dendritic cells perform different tasks in the skin immune system. Langerhans cell generated from $\mathrm{CD} 34^{+}$precursors were found to stimulate $\mathrm{T}$ cell responses, whereas interstitial dermal-like dendritic cells induced antibody secretion from B cells [11]. In support of this finding, migratory Langerhans cells are localized deep in the T cell area; in contrast, dermal dendritic cells accumulate around B cell follicles [24]. Currently, there is consensus that all skin dendritic cells subsets, Langerhans cells and both dermal dendritic cell subsets, are major players of the skin immune system. However, functional differences might exist and need to be examined.

Langerhans cell functions relevant to cancer immunotherapy: induction of cytotoxic $\mathrm{T}$ cell responses in vitro

Langerhans cells are powerful inducers of $\mathrm{CD}^{+} \mathrm{T}$ cell responses, yet it was long unclear if they are capable of cross-presenting exogenous antigen to $\mathrm{CD}^{+} \mathrm{T}$ cells. Studies performed with Langerhans cells generated from CD34 ${ }^{+}$ precursors demonstrated that Langerhans cell-like cells were able to capture apoptotic tumor cells and stimulate autologous $\mathrm{CD}^{+} \mathrm{T}$ cell responses in vitro $[9,38]$. In one of the studies, Langerhans cell-like cells proved to be superior to in vitro generated interstitial dermal dendritic cells in the induction of cytotoxic $\mathrm{T}$ cell responses [38]. In another study Langerhans cells derived from CD $34^{+}$precursors were also efficient in cross-presenting protein antigen provided that they had been stimulated with IFN- $\gamma$ [30]. We reported recently that Langerhans cells isolated from epidermis or emigrated from skin explants cross-presented soluble protein or cell-associated antigen on MHC-class I molecules to $\mathrm{CD}^{+} \mathrm{T}$ cells. Activated $\mathrm{CD} 8^{+} \mathrm{T}$ cells produced IFN- $\gamma$ upon restimulation and exerted cytotoxic activity [53].

Langerhans cell functions relevant to cancer immunotherapy: induction of cytotoxic T cell responses in vivo

From the in vitro studies mentioned above it became obvious that Langerhans cells are equipped with the machinery to 
stimulate cytotoxic T cells. However, not much is known about the efficiency of these $\mathrm{T}$ cells to kill tumor and infected cells in vivo. Immunization strategies through the skin became popular in the last few years since they might be an easy and cheap, and perhaps more efficient approach to load skin dendritic cells with antigen in situ. Application of antigen onto the skin together with adjuvants induced potent $\mathrm{CD}^{+}$and $\mathrm{CD}^{+} \mathrm{T}$ cell responses $[36,62]$. So far, the question, which skin dendritic cell subset mediates the $\mathrm{T}$ cell response had not been adequately addressed, mainly due to the lack of suitable experimental tools. We reported recently that protein antigen applied onto barrier-disrupted skin induced powerful long-lasting cytotoxic $\mathrm{CD}^{+} \mathrm{T}$ cell responses that could be aimed at transplantable melanoma. In this model, Langerhans cells were indeed required for the induction of anti-tumor responses as evidenced by the use of Langerhans cell-depleted mice: topically applied protein antigen was cross-presented to $\mathrm{CD}^{+} \mathrm{T}$ cells in the draining lymph nodes by epidermis-derived Langerhans cells, though not in an exclusive fashion. Other skin dendritic cell subsets also contributed to the immune response [54]. We therefore concluded that dermal dendritic cells may participate in the activation of $\mathrm{T}$ cells when they gain access to epicutaneously applied antigen which is likely to happen when antigen doses are high.

It should be mentioned, though, that many studies (including some of our own work) were or are being conducted in the highly useful "OT mouse model", where ovalbumin (OVA) peptide-specific, MHC I- (OT-I cells) and MHC II (OT-II)-restricted T cells are used as a convenient read-out. One must take into account, however, that these OT cells are highly sensitive, being responsive to antigen even at picomolar levels. For this reason it is mandatory, to extend such studies and measure the responses of the few endogenous antigen-specific $\mathrm{T}$ cells, rather than of the many adoptively transferred OT cells. Indeed, even under such experimental conditions was epicutaneous immunization able to induce protective immunity in that it delayed the growth of an experimentally transferred tumor [54]. Nonetheless, much more work needs to be done along these lines. In addition, studies must be done in tumor models that behave more like tumors in human patients, particularly in that they arise spontaneously.

\section{Dendritic cell-based immunotherapy of cancer}

Cancer develops when normal tissue cells undergo mutagenic alterations which allow them to overcome the controls of cell cycle. Accordingly, many tumor antigens are normal self-antigens for which the immune system has successfully established tolerance resulting in ignorance of the tumors by the immune system. To solve this hazardous situation the immune system has to be instructed to overcome tolerance and attack the tumor cells. The unique ability of dendritic cells to activate naïve $\mathrm{T}$ cells makes them prime candidates for immunotherapeutical approaches and therefore many, though not enough, clinical trials are currently ongoing which aim at harnessing their properties [49].

Transfer of in vitro generated dendritic cells

For immunotherapeutical trials, dendritic cells are generated in culture from either monocytes or $\mathrm{CD} 34^{+}$precursors isolated from cancer patients and loaded with tumor antigens in various ways such as co-culture with killed tumor cells, incubation with peptides or transfection with mRNA encoding for tumor antigens [35, 45]. Fully mature dendritic cells are injected subcutaneously into patients where they migrate to draining lymph nodes to stimulate $\mathrm{T}$ cells specific for tumor antigens. One of the major problems in these trials is the poor migration of dendritic cells. Indeed, most of the injected dendritic cells remain at the injection site and undergo apoptosis and very few (under 5\%) make it to the lymphoid organs [58]. A recent report demonstrated that the migration of injected dendritic cells can be improved by conditioning the injection site with either dendritic cells or proinflammatory cytokines like TNF- $\alpha$ [29]. In a mouse model that closely resembled the human dendritic cell trials, we tested the effect of pre-treating the dendritic cell application site with various inflammatory stimuli. We observed minor increases in the migration efficacy of fully mature bone marrow derived dendritic cells with a variety of toll like receptors (TLR) ligands and with gentle mechanical stress applied to the skin such as tape-stripping (i.e., removal of stratum corneum with adhesive tape). Interestingly, the corresponding $\mathrm{T}$ cell responses seemed hardly affected indicating that increased numbers of dendritic cells may not correlate with stronger $\mathrm{T}$ cell responses under all circumstances (C.H. Tripp, manuscript in preparation). This inaptness of dendritic cells to leave the injection site might be one of the reasons why the immune responses measured in treated patients are limited, however, there are many other causes for the lack of potent $\mathrm{T}$ cell responses. Nevertheless, some of the patients do show partial to complete clinical responses and survival times appear to be clearly prolonged [15] which strongly argues for perseverance in improving immunotherapeutical strategies involving dendritic cell transfer.

Strategies for immunizing cancer patients through resident dendritic cells

An alternative attractive approach is to harness the resident dendritic cells in the patients, thereby avoiding the 
cumbersome isolation and culture of precursor cells. The idea is to target tumor antigen to dendritic cells in patients in several ways. First of all, epicutaneous immunization seems suitable because antigen is deposited directly above the network of Langerhans cells and should therefore readily gain access to these cells. Indeed, it was shown that topically applied antigen induced $\mathrm{CD}^{+}$and $\mathrm{CD}^{+} \mathrm{T}$ cell responses in the skindraining lymph nodes, most probably through presentation by migratory skin dendritic cells [36, 62]. In several studies peptides or protein antigens were applied either onto barrier-disrupted skin [46] which is achieved by repeated application of adhesive tape onto the skin [20], or on untreated skin in combination with adjuvants like cholera toxin or TLR ligands [22, 25, 39]. We reported recently that protein antigen applied onto tape stripped skin induced proliferation of $\mathrm{CD} 4^{+}$and $\mathrm{CD} 8^{+} \mathrm{T}$ cells and development of long-lasting cytotoxic $\mathrm{T}$ cells. Immunization through tape stripped skin inhibited tumor growth and efficiency could be further improved by mixing the antigen into TLR-7 ligand containing Aldara ${ }^{\mathrm{TM}}$ (imiquimod) cream. Furthermore, we demonstrated that Langerhans cells presented the tumor antigen in the draining lymph nodes [54]. The importance of epicutaneous immunization for cancer immunotherapy became obvious recently in a first trial performed with this technique in tumor patients. Tumor-specific peptides applied onto barrier-disrupted skin stimulated $\mathrm{CD} 8^{+} \mathrm{T}$ cell proliferation and effector function that could mediate infiltration and regression of some tumor lesions [63]. Moreover, the potential value of Langerhans cells for immunotherapy was highlighted by Banchereau's group both by the in vitro demonstration of a strong CTL-inducing capacity of human Langerhans cells [9] and by a series of clinical trials in melanoma patients, where CD34-derived populations were used that contained Langerhans cell-like dendritic cells [16].

A powerful means to potentiate such responses would be to conjugate antigens to antibodies that specifically bind to the cell surface of dendritic cells [56]. Interesting candidates for targeting approaches are members of the C-type lectin receptor family, such as DEC-205/CD-205, langerin/ CD207, dectin-2. Antigens targeted to these receptors were presented much more efficiently to $\mathrm{T}$ cells than unconjugated soluble antigen, and, when dendritic cell-activating stimuli were concomitantly provided, strong immunity ensued $[6,10,21,28]$. Though usually performed by intradermal injection of the conjugates, such targeting strategies have not been studied yet in the specific context of the skin. This prompted us to study in more detail the very first step in epicutaneous immunization, namely the uptake of topically applied antigen into skin dendritic cells, particularly Langerhans cells.

\section{Recent studies on the mechanism of immunization through the skin}

Epicutaneous immunization with protein antigen

We wanted to visualize how well a protein antigen applied in a cream onto tape stripped skin is taken up by Langerhans cells in situ. For this purpose we used OVA protein conjugated to the fluorescent label Alexa 488. After repeated application of adhesive tape onto ear skin of mice to disturb the skin barrier, we applied either PBS or $100 \mu \mathrm{g}$ OVAAlexa 488 in cream. After overnight incubation epidermal cell suspensions were prepared from ear skin by trypsinization. Around $20 \%$ of the MHC-class $\mathrm{II}^{+}$Langerhans cells were positive for OVA-Alexa 488 (Fig. 1a). Not unexpectedly, a substantial proportion of keratinocytes also bound OVA-Alexa. When we checked Langerhans cells in situ in epidermal sheet specimens for capture of OVA-Alexa after epicutaneous immunization, we were unable to detect OVAAlexa 488 in the Langerhans cells. This was most probably due to low amounts of OVA taken up into the cells (data not shown). Subsequently, we wished to determine whether Langerhans cells would transport OVA-Alexa 488 during migration. Skin explants obtained from mice immunized with PBS or OVA-Alexa 488 were cultured on medium for $72 \mathrm{~h}$. Dendritic cells that migrated into the medium were examined for the presence of topically applied antigen. The majority of them were epidermal Langerhans cells as determined by coexpression of the adhesion molecule Ep-CAM/CD326 and the C-type lectin langerin/CD207. Most of the migratory Ep$\mathrm{CAM}^{+}$Langerhans cells carried OVA-Alexa 488 when leaving the skin explants (Fig. 1b). CD11 ${ }^{+} /$Ep$^{-C} \mathrm{AM}^{-}$cells, that comprise langerin $^{-}$as well as langerin ${ }^{+}$dermal dendritic cells, also took up OVA to some extent (Fig. 1b). These populations were too small, however, as to allow a reliable comparative evaluation of their antigen uptake and antigen carriage properties. As we have demonstrated before, application of $500 \mu \mathrm{g}$ OVA in cream onto barrier-disrupted skin led to proliferation of antigen-specific $\mathrm{CD}^{+} \mathrm{T}$ cells in vivo [54]. Therefore, we wondered whether such a small amount of $100 \mu \mathrm{g}$ OVA, that was applied in the experiments described above, would also induce $\mathrm{T}$ cell activation. To this end, we applied graded doses of OVA in cream onto tape stripped skin and measured proliferation of intravenously injected antigen-specific $\mathrm{CD} 4^{+}$and $\mathrm{CD} 8^{+} \mathrm{T}$ cells. Maximum proliferation of $\mathrm{CD}^{+}$and $\mathrm{CD}^{+} \mathrm{T}$ cells in skin-draining lymph nodes was already observed with as low amounts as $100 \mu \mathrm{g}$ 
Fig. 1 Langerhans cells capture and present protein antigen to T cells. a Ear skin of C57BL/6 mice was tape stripped ten times before either PBS or $100 \mu \mathrm{g}$ OVA-Alexa 488 were applied in cream. After overnight treatment, skin was trypsinized to isolate epidermal cells, followed by MHC-class II staining. The histogram shows the fluorescence intensity of OVA-Alexa 488 (thick line) versus PBS (thin line) in MHC-class $\mathrm{II}^{+}$Langerhans cells $(n=2)$. b Ear skin of C57BL/6 mice was treated as in a. After overnight treatment ear skin explants were cultured on medium for 3 days and migratory dendritic cells were identified by gating on CD11 ${ }^{+}$. Most migratory cells are Langerhans cells that are double-positive for Ep-CAM and langerin (lower right). Both Ep-CAM ${ }^{+}$and Ep$\mathrm{CAM}^{-}$cells take up the antigen (upper panels). Histogram

shows the fluorescence intensity of OVA-Alexa 488 (thick line) versus PBS (thin line) in Ep-

$\mathrm{CAM}^{+}$cells $(n=2)$. $\mathbf{c}$ Ear skin of C57BL/6 mice was tape stripped or left untreated and immunized with either PBS or various amounts of OVA in cream. $1 \times 10^{6}$ CFSE-labeled OT-I or OT-II T cells were injected intravenously into immunized mice. Three days later, skin-draining lymph nodes were analyzed for $\mathrm{T}$ cell proliferation (groups of three mice)
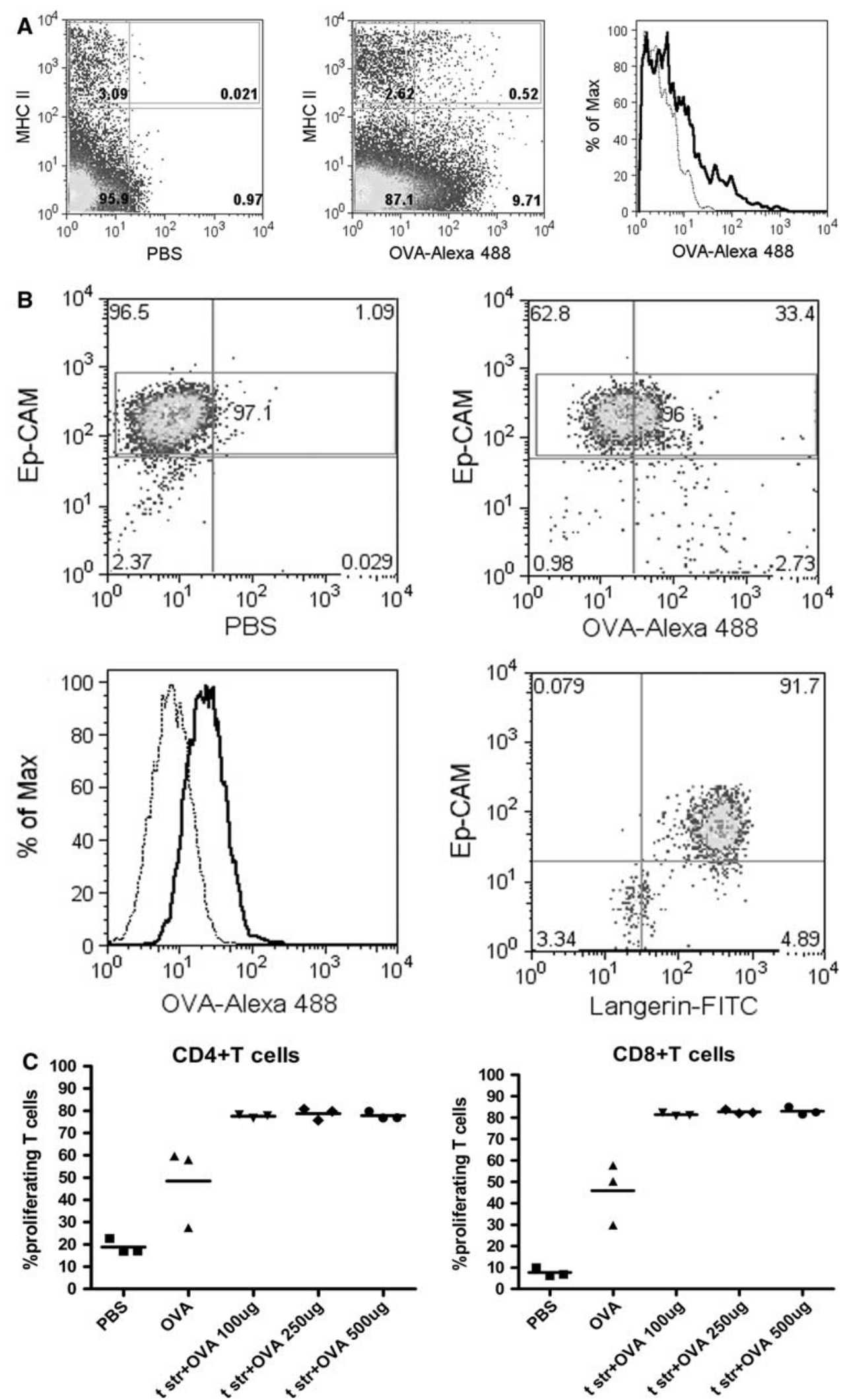

of OVA (Fig. 1c). We directly demonstrate here the uptake and carriage of a topically administered protein antigen by epidermal Langerhans cells in situ. This is the precondition that Langerhans cells can present these antigens in the lymph nodes, and that this capacity could ultimately be harnessed for clinical immunization purposes. 
Epicutaneous immunization with targeting antibody against skin dendritic cells

In an attempt to combine epicutaneous immunization with the dendritic cell targeting strategy we performed experiments in which we administered targeting antibodies topically onto the epidermis. For this purpose we used monoclonal antibodies against CD205/DEC-205 (clone NLDC-145) and CD207/langerin (clone L31) and applied them onto tape stripped ear skin for a few hours or overnight. These purified antibodies were used as surrogates for antibody-antigen conjugates that would eventually serve as a vaccine. With as low amounts as $10 \mu \mathrm{g}$ of anti-langerin antibody we noticed that most Langerhans cells captured the antibody. With increasing amounts of antibody the staining intensity was enhanced in Langerhans cells in the epidermis as observed by immunofluorescence on epidermal sheets (Fig. 2a). We performed skin explant cultures after topical application of the targeting antibodies against DEC-205 and langerin on tape stripped skin. More than half of the langerin ${ }^{+}$cells, containing Langerhans cells and the dermal langerin ${ }^{+}$dendritic cells, were positive for the targeting DEC-205 antibody. In contrast, the targeting antibody against langerin was detected in only a small proportion of the langerin ${ }^{+}$cells that migrated out of skin explants indicating a less efficient antibody capture (Fig. 2b). To further dissect the subsets of migratory skin dendritic cells after epicutaneous immunization with targeting antibody NLDC-145, we used CD103 as a marker to discriminate between $\mathrm{CD}_{103^{-}}$Langerhans cells from the epidermis and $\mathrm{CD}_{103}{ }^{+}$dermal langerin ${ }^{+}$dendritic cells as described recently [8]. We found that both populations captured the targeting antibody NLDC-145. The deeper lying dermal dendritic cells did not take up antibody, possibly as a result of inefficient diffusion of targeting antibody (Fig. 3). These data emphasize that, indeed, targeted delivery of protein antigen via the surface of the skin can improve the uptake by Langerhans cells and, as inferred from the literature [6], thereby augment ensuing $\mathrm{T}$ cell responses.

\section{Conclusion}

Epicutaneous immunization with either protein antigen or antigen conjugated to targeting antibodies are new promising approaches to improve dendritic cell immunotherapy. As we have shown earlier, application of protein antigen on barrier-disrupted skin induces proliferation of $\mathrm{CD}^{+} \mathrm{T}$ cells which differentiate into long-lasting effector $\mathrm{T}$ cells. The resulting cytotoxic $\mathrm{T}$ cell response inhibited the growth of
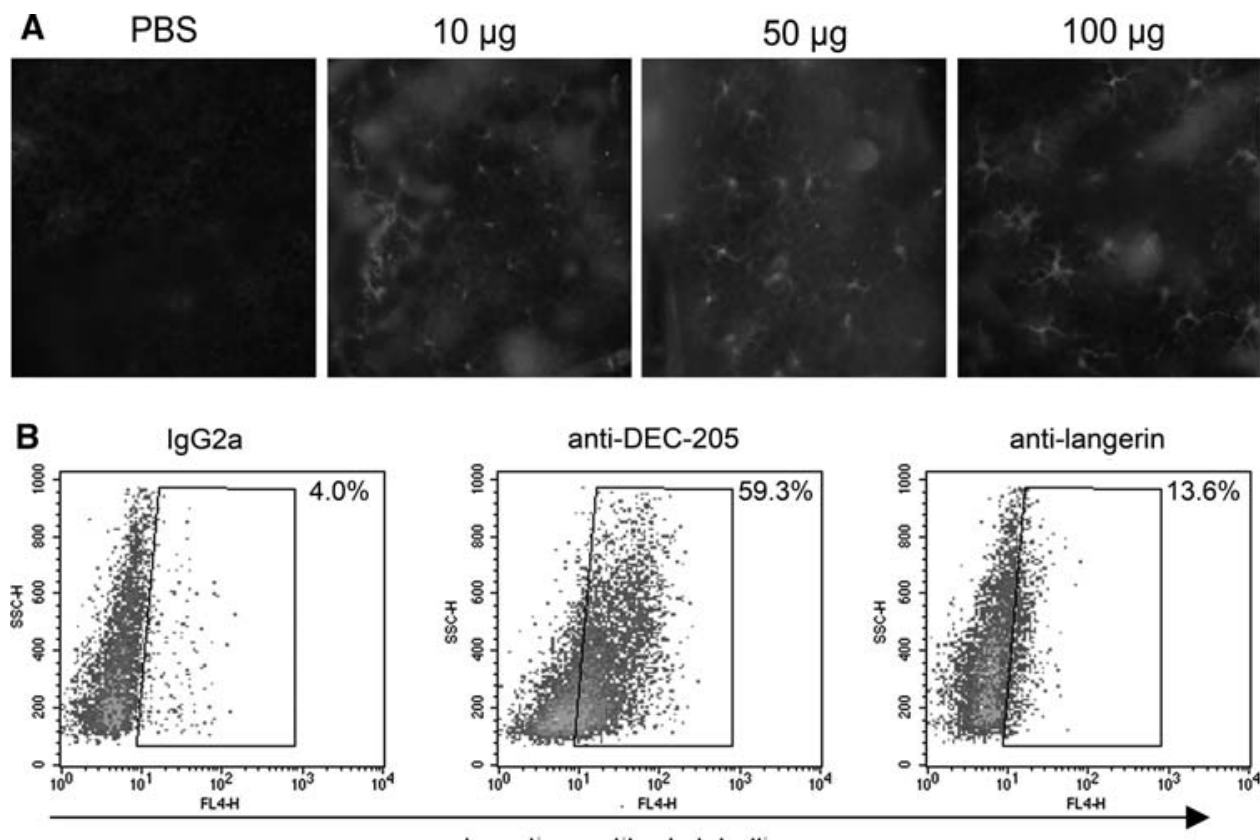

targeting antibody labelling

Fig. 2 Langerhans cells capture targeting antibodies against DEC-205 and langerin. a After repeated $(8 \times)$ tape-stripping, filter paper discs (8 $\mathrm{mm}$ diameter) soaked with PBS or 10-100 $\mu \mathrm{g}$ of langerin targeting antibody (clone L31, $20 \mu \mathrm{l} /$ disc) were applied for $3 \mathrm{~h}$ onto the ears of C57BL/6 mice. Eighteen hours later epidermal sheets were stained with secondary antibody to visualize capture of targeting antibody $(n=3)$. b Ten micrograms of isotype control or targeting antibodies against DEC-205 (clone NLDC-145) and langerin (clone L31) were applied to the ears of BALB/c mice. After $3 \mathrm{~h}$ the dorsal halves of immunized ears were cultured for 3 days. Migratory cells were stained for intracellular expression of langerin (clone 929F3) and targeting antibodies were visualized with a fluorescently conjugated secondary antibody. Density plots show capture of targeting antibodies in gated langerin ${ }^{+}$migratory dendritic cells $(n=2)$ 
Fig. 3 Migratory skin dendritic cells transport targeting antibody. After repeated $(8 \times)$ tapestripping filter paper discs soaked with $10 \mu \mathrm{g}$ of antiDEC205 targeting antibody (clone NLDC-145) or IgG2a isotype control ( $20 \mu \mathrm{l} / \mathrm{disc})$ were applied onto the ears of BALB/c mice. Eighteen hours later the dorsal halves of immunized ears were cultured on medium for 3 days. Migratory cells were stained for CD103 and intracellular langerin (clone 929F3). Targeting antibody NLDC-145 was visualized with a fluorescently conjugated secondary antibody. Density plots show capture of targeting antibody on langerin $^{+}$(upper row) and langerin $^{-}$(lower row) migratory cells $(n=2$ for $\mathrm{BALB} / \mathrm{c}, n=1$ for C57BL/6)

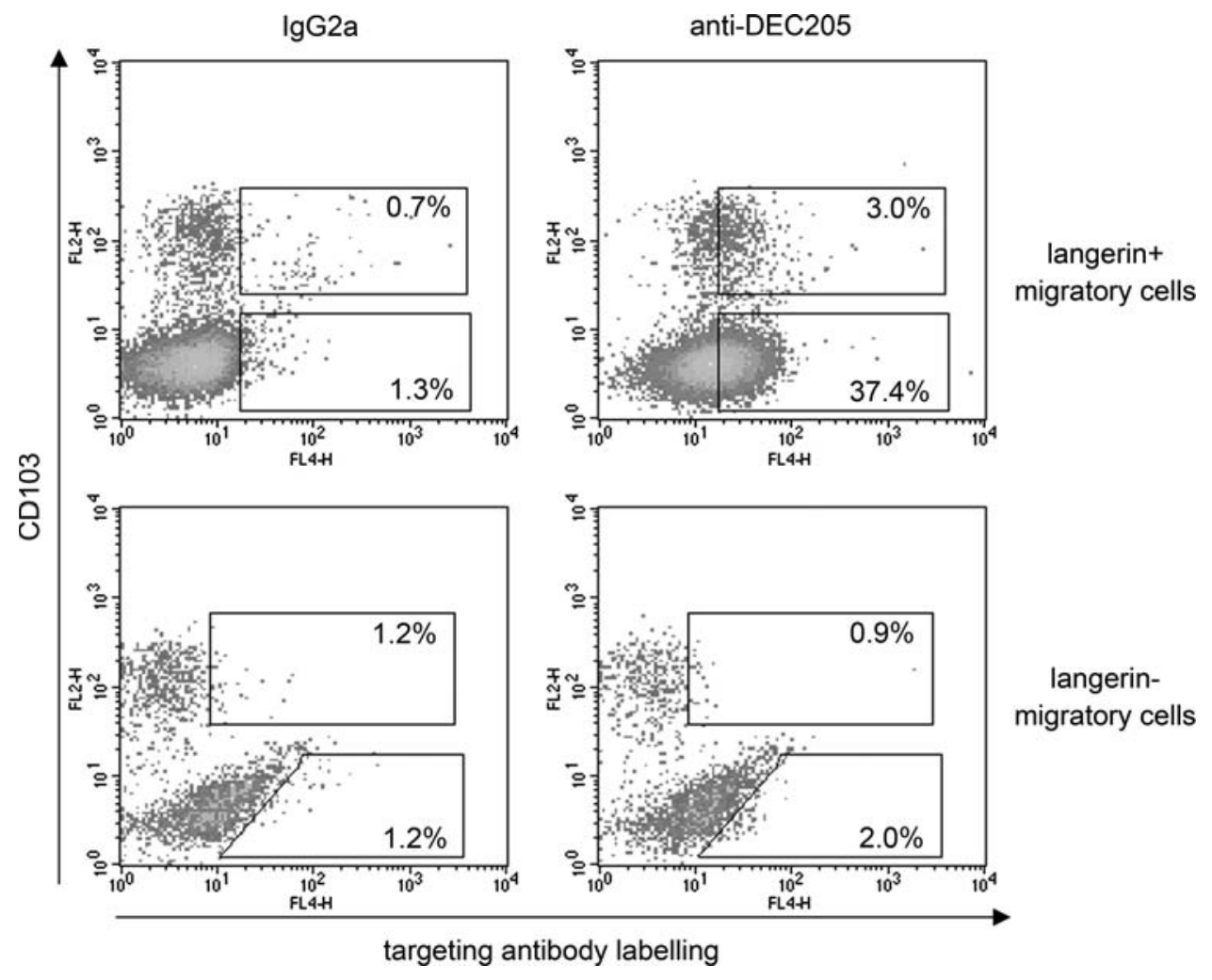

transplantable melanoma [54]. In the study here, we were interested in the visualization of antigen capture and transport by skin dendritic cells after application onto barrierdisrupted skin. For this purpose, we immunized mice with either fluorescently labeled protein antigen or targeting antibodies against dendritic cells. We demonstrate here that Langerhans cells were able to capture fluorescently labeled protein antigen in situ and that amounts of $100 \mu \mathrm{g}$ of OVA protein was sufficient to induce $\mathrm{CD} 4^{+}$and $\mathrm{CD}^{+} \mathrm{T}$ cell proliferation in skin-draining lymph nodes. Langerhans cells co-expressed langerin and Ep-CAM. Both markers were described to be specific for Langerhans cells [7, 8, 57]. The majority of dendritic cells migrating out of skin explant cultures are langerin ${ }^{+}$cells [52] which was believed to be a Langerhans cell specific marker until recently, when a new subset of langerin ${ }^{+}$dermal dendritic cells sitting in the upper part of the dermis and around hair follicles was discovered [8, 17, 37]. In our hands, the main skin dendritic cell subset that emigrated from skin explants prepared from tape stripped immunized ear skin, represented Langerhans cells, while only very few dermal dendritic cells migrated. Protein antigen was mostly detected in migratory Langerhans cells underlining their importance in epicutaneous immunization. Wang et al. reported recently that after immunization with fluorescently labeled protein onto hydrated intact ear skin, protein antigen can be mainly found in the epidermis and upper layers of the dermis on skin sections [61]. In support of this finding, we demon- strated recently that in Langerhans cell-depleted mice the anti-tumor responses were impaired, particularly when limiting amounts of protein antigen were used for epicutaneous immunization. Moreover, Langerhans cells sorted from skin-draining lymph nodes after epicutaneous immunization were able to cross-present protein antigen to $\mathrm{CD}^{+} \mathrm{T}$ cells [54]. It should be emphasized, however, that much less is known about the situation in human skin, that is thicker and more variable in terms of thickness as compared to the relatively uniform mouse skin. It remains to be seen, whether human Langerhans cells play an equally dominant role in epicutaneous immunization. Moreover, the contributions of the less well defined subsets of human dermal dendritic cells need to be studied thoroughly. They may certainly influence the final outcome.

The delivery of antigen directly and specifically to dendritic cells can be achieved by conjugating the protein antigen to antibodies against dendritic cells, such as DEC-205, langerin and dectin-2 [6, 10, 21]. In an attempt to target resident skin dendritic cells we topically applied antibodies against DEC-205 (clone NLDC-245) and an extracellular part of langerin (L31, [21]) onto barrier-disrupted skin. Indeed, we were able to detect the antibodies in Langerhans cells in situ in the epidermis. We observed that langerin ${ }^{+}$ cells were the main dendritic cells transporting antibodies against DEC-205 and langerin out of skin explants, comparable to immunization with protein antigen. The antibody against DEC-205 was captured more efficiently than the 
one against langerin which might be explained by the lower cell surface expression levels of langerin as compared to DEC-205 on skin dendritic cells. Furthermore, langerin is internalized during migration and maturation of Langerhans cells [13] so that in vivo bound langerin antibody could perhaps be more rapidly degraded than DEC-205 antibody during the 3-day culture period of skin explants. Langerhans cells and the recently described dermal langerin $^{+}$dendritic cells can be distinguished by the expression of the integrin CD103, epidermis-derived, "classical" Langerhans cells being CD103-negative [8]. CD103- Langerhans cells and dermal $\mathrm{CD}_{103^{+}} /$langerin $^{+}$dermal dendritic cell subsets were the main subsets targeted since they are localized in the epidermis and upper areas of the dermis, respectively, the latter sometimes close to hair follicles $[8$, 17]. Dermal langerin ${ }^{-}$dendritic cells, that also express DEC-205 [14, 18] and are situated deeper in the dermis, were inefficient in capturing the targeting antibody indicating a limited diffusion of the antibodies in the skin. In contrast, when targeting antibody against NLDC-145 was injected intradermally, all skin dendritic cell subsets are capable of binding, according to their surface expression of DEC-205 (V. Flacher, manuscript in preparation). Hence, the route of delivery will be a decisive factor for the capture and immune response induced by cutaneous immunization.

We are convinced that it is worthwhile to further study immunization strategies through the skin, particularly with antigen-antibody conjugates. According to the human situation, where the vast majority of dendritic cell immunotherapy studies are conducted with tumor patients (mostly melanoma and renal cell carcinoma), future studies in the mouse will be primarily done in tumor models. Nevertheless, this approach would be equally well applicable in the field of infectious diseases. First such attempts are already published [31]. Epicutaneous immunization would offer a number of advantages over conventional vaccination schemes including dendritic cell vaccination. (1) Even though injection of an immunogen is not a complicated procedure, the epicutaneous application of an antigen would still be simpler, safer, and possibly even feasible for selfadministration. (2) Given the problems with insufficient migration of intracutaneously injected dendritic cells to the draining lymph nodes due to a "cellular traffic jam" in the dermis $[1,59]$, it seems conceivable that targeting skin dendritic cells on a large area of skin may lead to a larger influx of immunogenic dendritic cells into the nodes and, as a consequence, to better immunity. (3) The preferential selection of Langerhans cells as antigen presenting cells in epicutaneous immunization may result in more robust cytotoxic anti-tumor responses [38]. (4) Antigen uptake and presentation in the absence of inflammation, i.e., of dendritic cell maturation stimuli, leads to peripheral tolerance [51]. It may be envisaged, that Langerhans cells might also be particularly suited to induce tolerance when targeted with autoantigens as they possess tolerogenic potential under certain experimental circumstances [47]. (5) Finally, one should also not forget, that the epicutaneous approach is certainly less costly than other immunization schemes.

\section{Outlook}

Many questions still need to be addressed and answered. First and foremost, we will need further information about possible differences in the function of skin dendritic cell subsets. Our poor knowledge on the various dendritic cell types in the dermis needs to catch up with the relatively better developed knowledge on epidermal Langerhans cells. This will be particularly important in human skin. Then, conventional skin injection protocols need to be compared side-by-side with epicutaneous immunization protocols in mouse models. Transfer of this knowledge to design protocols for human cancer patients will require solutions for several open questions. (1) How can one optimize the form of epicutaneous application? Expertise from the pharmaceutical industry will have to be combined with Langerhans cell research to achieve a maximal penetration of antigen into the epidermis and uptake into Langerhans cells. (2) What are the best adjuvants for epicutaneous immunization? We used tape-stripping as an inflammatory stimulus. The most "popular" candidate would be imiquimod, a TLR $7 / 8$ ligand that is widely used in the clinic (Aldara ${ }^{\circledR}$ ) and that has already been shown to augment dendritic cell migration [33]. (3) Little is known about the induction of regulatory $\mathrm{T}$ cells by Langerhans cells except that Langerhans cells from inflamed skin can indeed lead to an increase in regulatory T cells [26]. Nothing is known about interactions of skin dendritic cells with myeloid-derived suppressor cells [32]. Notwithstanding these uncertainties, it must be maintained that, at least in our above-described tumor models such down-regulatory pathways-if induced—did not prevent the protective effect [54].

Some of this necessary research is ongoing, some of it should be tackled soon. We are convinced that at some point we will indeed be able to selectively harness the immunogenic and/or tolerogenic potential of Langerhans cells in therapeutic or prophylactic protocols.

\section{Methods}

Mice

Breeding pairs of the inbred mouse strains C57BL/6 and $\mathrm{BALB} / \mathrm{c}$, as well as OT-I mice and OT-II mice expressing transgenic $\mathrm{V} \alpha 2 / \mathrm{V} \beta 5.1 / 5.2 \mathrm{~T}$ cell receptors specific for $\mathrm{K}^{\mathrm{b}}+\mathrm{OVA}_{257-264}$ and I-A $\mathrm{A}^{\mathrm{b}}+\mathrm{OVA}_{323-339}[3,19]$ were obtained 
from Charles River (Sulzfeld, Germany). All mice were bred at the animal facility of the Innsbruck Medical University and used for experiments at 7-12 weeks of age. All experimental protocols were approved by Austrian Ethics Committee and performed according to institutional guidelines.

Epicutaneous immunization with OVA protein

Ear skin of C57BL/6 mice was tape stripped ten times before we applied either PBS or $100 \mu$ g OVA-Alexa 488 (Invitrogen-Molecular Probes, Eugene, OR, USA), mixed with Ultrasicc ${ }^{\mathrm{TM}}$ cream (Intendis, Vienna, Austria) onto each ear. After overnight treatment with PBS or OVAAlexa 488 we incubated ear skin on $0.8 \%$ trypsin (Merck, Germany) to isolate epidermal cell suspensions. Langerhans cells were identified with an anti-MHC-class II mAb (clone M5/114, BD Biosciences, San Jose, CA, USA) and analyzed by FACS. For analysis of migratory dendritic cells from explant cultures see below. Gentle tape-stripping, as performed in our experiments, means the removal of the stratum corneum by means of adhesive tape and thereby the generation of inflammation [20]. Langerhans cell are not extracted by this treatment in contrast to earlier, harsher protocols [55].

Epicutaneous immunization with targeting antibodies

After repeated $(8 \times)$ tape-stripping, filter paper discs $(8 \mathrm{~mm}$ diameter) soaked with 10-100 $\mu \mathrm{g}$ of anti-DEC-205 (clone NLDC145, Invitrogen, Austria) or anti-langerin (clone L31, kind gift of R. Steinman, Rockefeller University, NY, USA [12]) targeting antibodies $(20 \mu \mathrm{l} / \mathrm{disc})$ were applied for $3 \mathrm{~h}$ or overnight onto the ears of $\mathrm{BALB} / \mathrm{c}$ or $\mathrm{C} 57 \mathrm{BL} / 6$ mice. Ear skin was used for preparation of epidermal sheets for immunofluorescence stainings or skin explant cultures.

\section{Skin explant cultures}

Complete culture medium used for skin explant cultures was RPMI-1640 (PAA, Linz, Austria) supplemented with $10 \%$ heat-inactivated fetal bovine serum (Lonza-Biowhittaker, Belgium), $2 \mathrm{mM}$ L-glutamine (Invitrogen-Gibco, Paisley, Scotland), $50 \mu \mathrm{g} / \mathrm{ml}$ gentamicin (PAA) and $50 \mu \mathrm{M}$ 2-mercaptoethanol (Sigma-Aldrich, St Louis, MO, USA). After treatment with PBS, OVA-Alexa 488 or targeting antibodies for $3 \mathrm{~h}$ or overnight, the dorsal halves of the ears were cultured on medium for 3 days as described earlier [34]. Cells that had migrated into the medium (typically between 10,000 and 30,000 DC per ear half) were harvested and stained with PE-conjugated anti-Ep-CAM/ CD326 (clone G8.8, BD), anti-langerin (clone 929F3, Dendritics, Lyon, France) or PE-conjugated CD103 (clone M290, BD). In experiments where uptake of OVA-Alexa
488 was studied, dendritic cells were identified by staining with anti-CD11c. Targeting antibodies were visualized by goat anti-rat Ig/APC secondary antibody (BD). For langerin staining or visualization of targeting antibody, cells were permeabilized with BD Cytofix/Cytoperm ${ }^{\mathrm{TM}}$ Fixation/ Permeabilization Solution Kit (BD).

Immunofluorescence stainings of the skin

After overnight incubation with targeting antibodies, ear skin was incubated on $0.5 \mathrm{M}$ ammoniumthiocyanate for $20 \mathrm{~min}$. Epidermal sheets were peeled off, fixed in acetone for $20 \mathrm{~min}$ and stained for $1 \mathrm{~h}$ at $37^{\circ} \mathrm{C}$ with chicken anti-rat Ig/Alexa 594 secondary antibody (Invitrogen).

In vivo proliferation of $\mathrm{T}$ cells after epicutaneous immunization

Spleens and lymph nodes from OT-I and OT-II mice were pressed through a cell strainer and red blood cells were lysed with ammonium chloride buffer. Cells were then incubated with anti-CD8 or anti-CD4 mAb conjugated to magnetic beads (MACS $^{\mathrm{TM}}$, Miltenyi Biotec, BergischGladbach, Germany) and positively sorted with magnets (Miltenyi). Cell purity was routinely over $85 \%$. C57BL/6 mice were tape stripped 12 times on ear skin and on the same day $1 \times 10^{6} \mathrm{~T}$ cells isolated from OT-I and OT-II mice were labeled with $0.2 \mu \mathrm{M}$ CFSE and injected intraveneously. One day later, PBS or $500 \mu \mathrm{g}$ unconjugated OVA (Sigma-Aldrich) was applied onto untreated, or varying doses of OVA were applied onto tape stripped ear skin. T cell proliferation was measured 3 days later in skin-draining lymph nodes by analyzing dilution of CFSE by flow cytometry as described earlier [27].

Acknowledgments This work was funded by the Austrian Science Fund (FWF project L120-B13 to N. Romani) and by the "Kompetenzzentrum Medizin Tirol-CEMIT" (project KMT-03b of N. Romani). Furthermore, the constant support of the Tyrolean Provincial Hospital Company (Tilak Ges.m.b.H.) is greatly appreciated. We thank Jae Y. Jung from the Malaghan Institute for Medical Research, Wellington, NZ for technical assistance. We are particularly indebted to Prof. Peter Fritsch, Head of Department, for his continued support and encouragement.

Open Access This article is distributed under the terms of the Creative Commons Attribution Noncommercial License which permits any noncommercial use, distribution, and reproduction in any medium, provided the original author(s) and source are credited.

\section{References}

1. Adema GJ, de Vries IJ, Punt CJ, Figdor CG (2005) Migration of dendritic cell based cancer vaccines: in vivo veritas? Curr Opin Immunol 17:170-174 
2. Allan RS, Smith CM, Belz GT, Van Lint AL, Wakim LM, Heath WR, Carbone FR (2003) Epidermal viral immunity induced by CD $8 \alpha^{+}$dendritic cells but not by Langerhans cells. Science 301:1925-1928

3. Barnden MJ, Allison J, Heath WR, Carbone FR (1998) Defective TCR expression in transgenic mice constructed using cDNAbased alpha- and beta-chain genes under the control of heterologous regulatory elements. Immunol Cell Biol 76:34-40

4. Bennett CL, van Rijn E, Jung S, Inaba K, Steinman RM, Kapsenberg ML, Clausen BE (2005) Inducible ablation of mouse Langerhans cells diminishes but fails to abrogate contact hypersensitivity. J Cell Biol 169:569-576

5. Bennett CL, Noordegraaf M, Martina CAE, Clausen BE (2007) Langerhans cells are required for efficient presentation of topically applied hapten to T Cells. J Immunol 179:6830-6835

6. Bonifaz LC, Bonnyay DP, Charalambous A, Darguste DI, Fujii SI, Soares H, Brimnes MK, Moltedo B, Moran TM, Steinman RM (2004) In vivo targeting of antigens to maturing dendritic cells via the DEC-205 receptor improves T cell vaccination. J Exp Med 199:815-824

7. Borkowski TA, Nelson AJ, Farr AG, Udey MC (1996) Expression of gp40, the murine homologue of human epithelial cell adhesion molecule (Ep-CAM), by murine dendritic cells. Eur J Immunol 26:110-114

8. Bursch LS, Wang L, Igyarto B, Kissenpfennig A, Malissen B, Kaplan DH, Hogquist KA (2007) Identification of a novel population of langerin ${ }^{+}$cell. J Exp Med 204:3147-3156

9. Cao T, Ueno H, Glaser C, Fay JW, Palucka AK, Banchereau J (2007) Both Langerhans cells and interstitial DC cross-present melanoma antigens and efficiently activate antigen-specific CTL. Eur J Immunol 37:2657-2667

10. Carter RW, Thompson C, Reid DM, Wong SYC, Tough DF (2006) Induction of $\mathrm{CD}^{+} \mathrm{T}$ cell responses through targeting of antigen to dectin-2. Cell Immunol 239:87-91

11. Caux C, Massacrier C, Vanbervliet B, Dubois B, Durand I, Cella M, Lanzavecchia A, Banchereau J (1997) CD34+ hematopoietic progenitors from human cord blood differentiate along two independent dendritic cell pathways in response to granulocyte-macrophage colony-stimulating factor plus tumor necrosis factor $\alpha .2$. Functional analysis. Blood 90:1458-1470

12. Cheong C, Idoyaga J, Do Y, Pack M, Park SH, Lee H, Kang YS, Choi JH, Kim JY, Bonito A, Inaba K, Yamazaki S, Steinman RM, Park CG (2007) Production of monoclonal antibodies that recognize the extracellular domain of mouse Langerin/CD207. J Immunol Methods 324:48-62

13. Douillard P, Stoitzner P, Tripp CH, Clair-Moninot V, Ait-Yahia S, McLellan A, Eggert A, Romani N, Saeland S (2005) Mouse lymphoid tissue contains distinct subsets of Langerin/CD207+ dendritic cells, only one of which represents epidermal-derived Langerhans cells. J Invest Dermatol 125:983-994

14. Duraiswamy N, Tse Y, Hammerberg C, Kang S, Cooper KD (1994) Distinction of class II MHC ${ }^{+}$Langerhans cell-like interstitial dendritic antigen-presenting cells in murine dermis from dermal macrophages. J Invest Dermatol 103:678-683

15. Enk AH, Becker JC, Schuler G (2006) Immunotherapy of malignant melanoma-basic principles and novel therapeutic approaches. J Dtsch Dermatol Ges 4:635-644

16. Fay JW, Palucka AK, Paczesny S, Dhodapkar M, Johnston DA, Burkeholder S, Ueno H, Banchereau J (2006) Long-term outcomes in patients with metastatic melanoma vaccinated with melanoma peptide-pulsed CD34(+) progenitor-derived dendritic cells. Cancer Immunol Immunother 55:1209-1218

17. Ginhoux F, Collin M, Bogunovic M, Abel M, Leboef M, Helft J, Ochando JC, Kissenpfennig A, Malissen B, Grisotto M, Snoeck H, Randolph GJ, Merad M (2007) Blood-derived dermal langerin+ dendritic cells survey the skin in the steady state. J Exp Med 204:3133-3146
18. Henri S, Vremec D, Kamath A, Waithman J, Williams S, Benoist C, Burnham K, Saeland S, Handman E, Shortman K (2001) The dendritic cell populations of mouse lymph nodes. J Immunol 167:741-748

19. Hogquist KA, Jameson SC, Heath WR, Howard JL, Bevan MJ, Carbone FR (1994) T cell receptor antagonist peptides induce positive selection. Cell 76:17-27

20. Holzmann S, Tripp CH, Schmuth M, Janke K, Koch F, Saeland S, Stoitzner P, Romani N (2004) A model system using tape stripping for characterization of Langerhans cell-precursors in vivo. J Invest Dermatol 122:1165-1174

21. Idoyaga J, Cheong C, Suda K, Suda N, Kim JY, Lee H, Park CG, Steinman RM (2008) The Langerin/CD207 receptor on dendritic cells mediates efficient antigen presentation on MHC I and MHC II products in vivo. J Immunol 180:3647-3650

22. Kahlon R, Hu YX, Orteu CH, Kifayet A, Trudeau JD, Tan RS, Dutz JP (2003) Optimization of epicutaneous immunization for the induction of CTL. Vaccine 21:2890-2899

23. Kaplan DH, Jenison MC, Saeland S, Shlomchik WD, Shlomchik MJ (2005) Epidermal Langerhans cell-deficient mice develop enhanced contact hypersensitivity. Immunity 23:611-620

24. Kissenpfennig A, Henri S, Dubois B, Laplace-Builhé C, Perrin P, Romani N, Tripp CH, Douillard P, Leserman L, Kaiserlian D, Saeland S, Davoust J, Malissen B (2005) Dynamics and function of Langerhans cells in vivo: dermal dendritic cells colonize lymph node areas distinct from slower migrating Langerhans cells. Immunity 22:643-654

25. Klimuk SK, Najar HM, Semple SC, Aslanian S, Dutz JP (2004) Epicutaneous application of $\mathrm{CpG}$ oligodeoxynucleotides with peptide or protein antigen promotes the generation of CTL. J Invest Dermatol 122:1042-1049

26. Loser K, Mehling A, Loeser S, Apelt J, Kuhn A, Grabbe S, Schwarz T, Penninger JM, Beissert S (2007) Epidermal RANKL controls regulatory $\mathrm{T}$-cell numbers via activation of dendritic cells. Nat Med 12:1372-1379

27. Lyons AB (2000) Analysing cell division in vivo and in vitro using flow cytometric measurement of CFSE dye dilution. J Immunol Methods 243:147-154

28. Mahnke K, Guo M, Lee S, Sepulveda H, Swain SL, Nussenzweig M, Steinman RM (2000) The dendritic cell receptor for endocytosis, DEC-205, can recycle and enhance antigen presentation via major histocompatibility complex class II-positive lysosomal compartments. J Cell Biol 151:673-683

29. Martín-Fontecha A, Sebastiani S, Höpken UE, Uguccioni M, Lipp M, Lanzavecchia A, Sallusto F (2003) Regulation of dendritic cell migration to the draining lymph node: impact on T lymphocyte traffic and priming. J Exp Med 198:615-621

30. Matsuo M, Nagata Y, Sato E, Atanackovic D, Valmori D, Chen YT, Ritter G, Mellman I, Old LJ, Gnjatic S (2004) IFN-gamma enables cross-presentation of exogenous protein antigen in human Langerhans cells by potentiating maturation. Proc Natl Acad Sci USA 101:14467-14472

31. McKenzie R, Bourgeois AL, Frech SA, Flyer DC, Bloom A, Kazempour K, Glenn GM (2007) Transcutaneous immunization with the heat-labile toxin (LT) of enterotoxigenic Escherichia coli (ETEC): protective efficacy in a double-blind, placebo-controlled challenge study. Vaccine 25:3684-3691

32. Nagaraj S, Gabrilovich DI (2008) Tumor escape mechanism governed by myeloid-derived suppressor cells. Cancer Res 68:2561-2563

33. Nair S, McLaughlin C, Weizer A, Su Z, Boczkowski D, Dannull J, Vieweg J, Gilboa E (2003) Injection of immature dendritic cells into adjuvant-treated skin obviates the need for ex vivo maturation. J Immunol 171:6275-6282

34. Ortner U, Inaba K, Koch F, Heine M, Miwa M, Schuler G, Romani N (1996) An improved isolation method for murine migratory cutaneous dendritic cells. J Immunol Methods 193:71-79 
35. Palucka AK, Ueno H, Fay JW, Banchereau J (2007) Taming cancer by inducing immunity via dendritic cells. Immunol Rev 220:129-150

36. Partidos CD, Beignon AS, Mawas F, Belliard G, Briand JP, Muller S (2003) Immunity under the skin: potential application for topical delivery of vaccines. Vaccine 21:776-780

37. Poulin LF, Henri S, de Bovis B, Devilard E, Kissenpfennig A, Malissen B (2007) The dermis contains langerin ${ }^{+}$dendritic cells that develop and function independently of epidermal Langerhans cells. J Exp Med 204:3119-3131

38. Ratzinger G, Baggers J, de Cos MA, Yuan J, Dao T, Reagan JL, Münz C, Heller G, Young JW (2004) Mature human Langerhans cells derived from CD34+ hemopoietic progenitors stimulate greater cytolytic $\mathrm{T}$ lymphocyte activity in the absence of bioactive IL-12p70, by either single peptide presentation or cross-priming, than do dermal-interstitial or monocyte-derived dendritic cells. J Immunol 173:2780-2791

39. Rechtsteiner G, Warger T, Osterloh P, Schild H, Radsack MP (2005) Cutting edge: priming of CTL by transcutaneous peptide immunization with imiquimod. J Immunol 174:2476-2480

40. Ritter U, Meissner A, Scheidig C, Körner H (2004) CD8 $\alpha$ - and langerin-negative dendritic cells, but not Langerhans cells, act as principal antigen-presenting cells in leishmaniasis. Eur J Immunol 34:1542-1550

41. Romani N, Koide S, Crowley M, Witmer-Pack M, Livingstone AM, Fathman CG, Inaba K, Steinman RM (1989) Presentation of exogenous protein antigens by dendritic cells to T cell clones: intact protein is presented best by immature epidermal Langerhans cells. J Exp Med 169:1169-1178

42. Romani N, Holzmann S, Tripp CH, Koch F, Stoitzner P (2003) Langerhans cells-dendritic cells of the epidermis. APMIS 111:725-740

43. Romani N, Ebner S, Flacher V, Tripp CH, Heufler C, Clausen BE, Stoitzner P (2008) Langerhans cells-dendritic cells of the epidermis and other epithelia. In: Saeland S (ed) Recent advances in skin immunology. Research Signpost, Trivandrum. ISBN 978-81-3080276-3

44. Schuler G, Steinman RM (1985) Murine epidermal Langerhans cells mature into potent immunostimulatory dendritic cells in vitro. J Exp Med 161:526-546

45. Schuler G, Schuler-Thurner B, Steinman RM (2003) The use of dendritic cells in cancer immunotherapy. Curr Opin Immunol $15: 138-147$

46. Seo N, Tokura Y, Nishijima T, Hashizume H, Furukawa F, Takigawa M (2000) Percutaneous peptide immunization via corneum barrier-disrupted murine skin for experimental tumor immunoprophylaxis. Proc Natl Acad Sci USA 97:371-376

47. Shibaki A, Sato A, Vogel JC, Miyagawa F, Katz SI (2004) Induction of GVHD-like skin disease by passively transferred $\mathrm{T}$ cell receptor transgenic CD8+ T cells into keratin-14-ovalbumin transgenic mice. J Invest Dermatol 123:109-115

48. Steinman RM (2007) Dendritic cells: understanding immunogenicity. Eur J Immunol 37:S53-S60

49. Steinman RM, Banchereau J (2007) Taking dendritic cells into medicine. Nature 449:419-426

50. Steinman RM, Cohn ZA (1973) Identification of a novel cell type in peripheral lymphoid organs of mice. I. Morphology, quantitation, tissue distribution. J Exp Med 137:1142-1162
51. Steinman RM, Nussenzweig MC (2002) Avoiding horror autotoxicus: the importance of dendritic cells in peripheral T cell tolerance. Proc Natl Acad Sci USA 99:351-358

52. Stoitzner P, Holzmann S, McLellan AD, Ivarsson L, Stössel H, Kapp M, Kämmerer U, Douillard P, Kämpgen E, Koch F, Saeland S, Romani N (2003) Visualization and characterization of migratory Langerhans cells in murine skin and lymph nodes by antibodies against Langerin/CD207. J Invest Dermatol 120:266-274

53. Stoitzner P, Tripp CH, Eberhart A, Price KM, Jung JY, Bursch LS, Ronchese F, Romani N (2006) Langerhans cells cross-present antigen derived from skin. Proc Natl Acad Sci USA 103:77837788

54. Stoitzner P, Green LK, Jung JY, Price KM, Tripp CH, Malissen B, Kissenpfennig A, Hermans IF, Ronchese F (2008) Tumor immunotherapy by epicutaneous immunization requires Langerhans cells. J Immunol 180:1991-1998

55. Streilein JW, Lonsberry LW, Bergstresser PR (1982) Depletion of epidermal Langerhans cells and Ia immmunogenicity from tapestripped mouse skin. J Exp Med 155:863-871

56. Tacken PJ, de Vries IJ, Torensma R, Figdor CG (2007) Dendriticcell immunotherapy: from ex vivo loading to in vivo targeting. Nat Rev Immunol 7:790-802

57. Valladeau J, Ravel O, Dezutter-Dambuyant C, Moore K, Kleijmeer M, Liu Y, Duvert-Frances V, Vincent C, Schmitt D, Davoust J, Caux C, Lebecque S, Saeland S (2000) Langerin, a novel C-type lectin specific to Langerhans cells, is an endocytic receptor that induces the formation of Birbeck granules. Immunity 12:71-81

58. Verdijk P, Scheenen TW, Lesterhuis WJ, Gambarota G, Veltien AA, Walczak P, Scharenborg NM, Bulte JW, Punt CJ, Heerschap A, Figdor CG, de Vries IJ (2007) Sensitivity of magnetic resonance imaging of dendritic cells for in vivo tracking of cellular cancer vaccines. Int J Cancer 120:978-984

59. Verdijk P, Aarntzen EH, Punt CJ, de Vries IJ, Figdor CG (2008) Maximizing dendritic cell migration in cancer immunotherapy. Expert Opin Biol Ther 8:865-874

60. Waithman J, Allan RS, Kosaka H, Azukizawa H, Shortman K, Lutz MB, Heath WR, Carbone FR, Belz GT (2007) Skin-derived dendritic cells can mediate deletional tolerance of class I-restricted self-reactive T cells. J Immunol 179:4535-4541

61. Wang L, Bursch LS, Kissenpfennig A, Malissen B, Jameson SC, Hogquist KA (2008) Langerin expressing cells promote skin immune responses under defined conditions. J Immunol 180:47224727

62. Warger T, Schild H, Rechtsteiner G (2007) Initiation of adaptive immune responses by transcutaneous immunization. Immunol Lett 109:13-20

63. Yagi H, Hashizume H, Horibe T, Yoshinari Y, Hata M, Ohshima A, Ito T, Takigawa M, Shibaki A, Shimizu H, Seo N (2006) Induction of therapeutically relevant cytotoxic $\mathrm{T}$ lymphocytes in humans by percutaneous peptide immunization. Cancer Res 66:10136-10144

64. Zhao XY, Deak E, Soderberg K, Linehan M, Spezzano D, Zhu J, Knipe DM, Iwasaki A (2003) Vaginal submucosal dendritic cells, but not Langerhans cells, induce protective th1 responses to herpes simplex virus-2. J Exp Med 197:153-162 